\title{
EXPERIMENTS ON THE ORIGIN AND CONDUCTION OF THE CARDIAC IMPULSE
}

\author{
VII. SINOVENTRICULAR AND SINO-AURICULAR HEARTBLOCK *
}

\section{J. A. E. EYSTER, M.D., and WALTER J. MEEK, Ph.D.}

The criterion for sino-auricular heartblock in the mammalian heart that has been hitherto applied, both experimentally in the lower animals and clinically in man, is the occurrence of dropped beats in an otherwise regular auricular rhythm. The only exception to this comprises certain visual observations on hearts dying from asphyxia, made by Hering ${ }^{1}$ and others, the significance of which loses its value in the light of subsequent work (Eyster and $\mathrm{Meek}^{2}$ ). Neither the venous pulse nor the electrocardiogram in the higher animals gives evidence of activity in the sino-auricular node distinct from that of the auricle, and attempts to record by suspension methods in the exposed heart contraction of these two regions separately have been rewarded only with inconclusive results. It has seemed to us desirable therefore to carry out experimental procedures that should produce partial and complete sino-auricular block, if such conditions are indeed possible in the mammalian heart, and at the same time record separately the activity of the sino-auricular node and the auricles. This we have done in the present series of experiments by recording the action currents directly from the exposed dog's heart with the string galvanometers.

We have reviewed the experimental and clinical literature of sinoauricular block in two preceding publications. ${ }^{3}$ Since the publication of the last paper, four additional clinical cases have been described by Levine. ${ }^{4}$ While there are reasons to regard the occurrence of dropped beats in an otherwise regular auricular thythm as reliable evidence of blocking of the excitation above the auricle, there are, of course, other possible interpretations of this phenomenon and we cannot at present state that we have undoubted proof that sino-auricular block may occur under any condition. The dropped beats may, for example, be due to failure of the pacemaker to generate excitations at certain periods, or to failure of the cardiac tissue to respond,

* Submitted for publication July 11, 1916.

* From the Physiological Laboratory of the University of Wisconsin.

1. Hering: Arch. f. d. ges. Physiol., 1900, 82, 1.

2. Eyster and Meek: Heart, 1914, 5, 137.

3. Eyster and Meek: Heart, 1912, 4, 59. Eyster and Evans: The Archives Int. MEd., 1915, 16, 832.

4. Levine: The Archives Int. Med., 1916, 17, 153. 
for reasons other than failure of conduction. It is the main purpose of this paper to furnish proof of the occurrence of partial and complete sino-auricular block in the mammalian heart.

In preceding papers of this series, especially the one immediately preceding, ${ }^{5}$ we have demonstrated that the normal cardiac impulse arising in the upper portion of the sino-auricular node is conducted to the right auricle and to the auriculoventricular node by two separate paths. There is thus sinoventricular conduction to be considered, as well as sino-auricular conduction, and the possibility of blocking in either one or both of these conducting paths.

\section{EXPERIMENTAL METHODS}

The experimental results to be reported in this paper are derived in part from certain of the experiments yielding data of another nature and reported in the preceding publication and in part from additional experiments. All the experiments were on dogs anesthetized with morphin and ether.

In nine preliminary experiments, the exposed sino-auricular region was subjected to torsion, ${ }^{6}$ to gradual clamping, either of the node itself or the node was pulled through a clamp and this tightened down on the surrounding structures, and to the application of nicotin and cocain, in solution, in increasing amounts to the node and contiguous tissues. Electrocardiograms were made from the extremities and comparisons of negativity in different regions of the heart carried out by the direct application of nonpolarizable electrodes to the heart. In none of these was any evidence of partial sino-auricular block obtained and no effort was made to constitute complete block. Torsion and gradual clamping of the node or contiguous tissue produced usually acceleration of the rate, premature beats, and if carried far enough, temporary or permanent removal of the pacemaker to the auriculoventricular node or the coronary sinus portion of this node. Nicotin and cocain produced at first slowing of the discharge of the sino-auricular node, later abolition of its function and removal of the pacemaker. These experiments, therefore, so far as the production of sino-auricular block are concerned, were entirely negative.

We then began a systematic effort to obtain evidence for or against the occurrence of sinus block by a series of experiments carried out as follows: On the exposed heart pairs of electrodes close together (within 1 or $2 \mathrm{~mm}$.) were placed on (1) the sino-auricular node, (2) on the right atrium and (3) on the ventricular portion of the auriculo-

5. Eyster, J. A. E.. and Meek, W. J.: The Archives Int. Med., 1916, 18, 775.

6. Erlanger and Blackman: Am. Jour. Physiol., 1907, 19, 125. These authors have reported the occurrence of dropped beats in artificially perfused rabbits' hearts as a result of this procedure. 
ventricular node. Each pair was so arranged that it could be connected to one of two string galvanometers and simultaneous records of the electrical negativity in any two of the above regions made at any time on the same photographic record. Mechanical systoles of the right auricular appendage and apex of the right ventricle were recorded on the same record. In this way we could determine the time interval of negativity between any two of these regions and at the same time determine whether these different regions were manifesting their usual sequence and rhythm. In other words, we have by this method a definite graphic record of the activities of these three regions, and the possibility of determining the relation between the activities of each. After determining the normal relation, gradual and progressive isolation of the sino-auricular node was carried out by

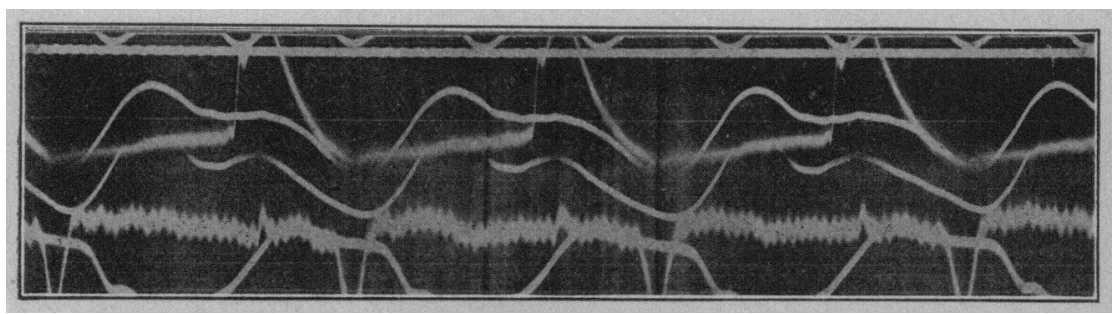

Fig. 1.- Normal beat immediately preceding the occurrence of partial sinoauricular and sinoventricular block in Experiment 34. The record shows, reading from top to bottom, (1) time record in one-fifth second intervals; (2) line made by signal pen; (3) record of mechanical systole of right auricle by lever of recording tambour in front of photographic registration apparatus; (4) shadow of galvanometer fiber connected to two electrodes, one on the upper part, the other on the midregion of the sino-auricular node (upstroke indicates initial negativity of the upper end of the node); (5) duplicate shadow cast by (3), to be ignored in interpretation of record; (6) shadow cast by tambour recording mechanical systole (by downstroke) of right ventricle; (7) galvanometer fiber connected to two points lying about $2 \mathrm{~mm}$. apart on the ventricular portion of the auriculoventricular node.

Previous to this record ligatures had been tied across the sulcus terminalis above and below the sino-auricular node and the tissues along the intercaval borders of the node crushed by clamping. As a result of these procedures the $S a-A v$ conduction time had increased from a normal of 0.022 of a second to its average value of 0.03 of a second, as shown in the record from which the figure is reproduced. The average $A s-V s$ is 0.18 of a second; the cycle length, 0.50 of a second.

cutting through the tissues around the node, by clamping and, in a few cases, by ligature. The methods employed for the cuts and for clamping are described in detail in the preceding paper. ${ }^{5}$ Usually we attempted to make as much permanent separation of tissue by cuts as could be done without causing removal of the seat of impulse formation from the sino-auricular node and then to subject the remainder, or part of the remainder, to gradual clamping, during which periods continuous records were made. Most of our attention was directed 

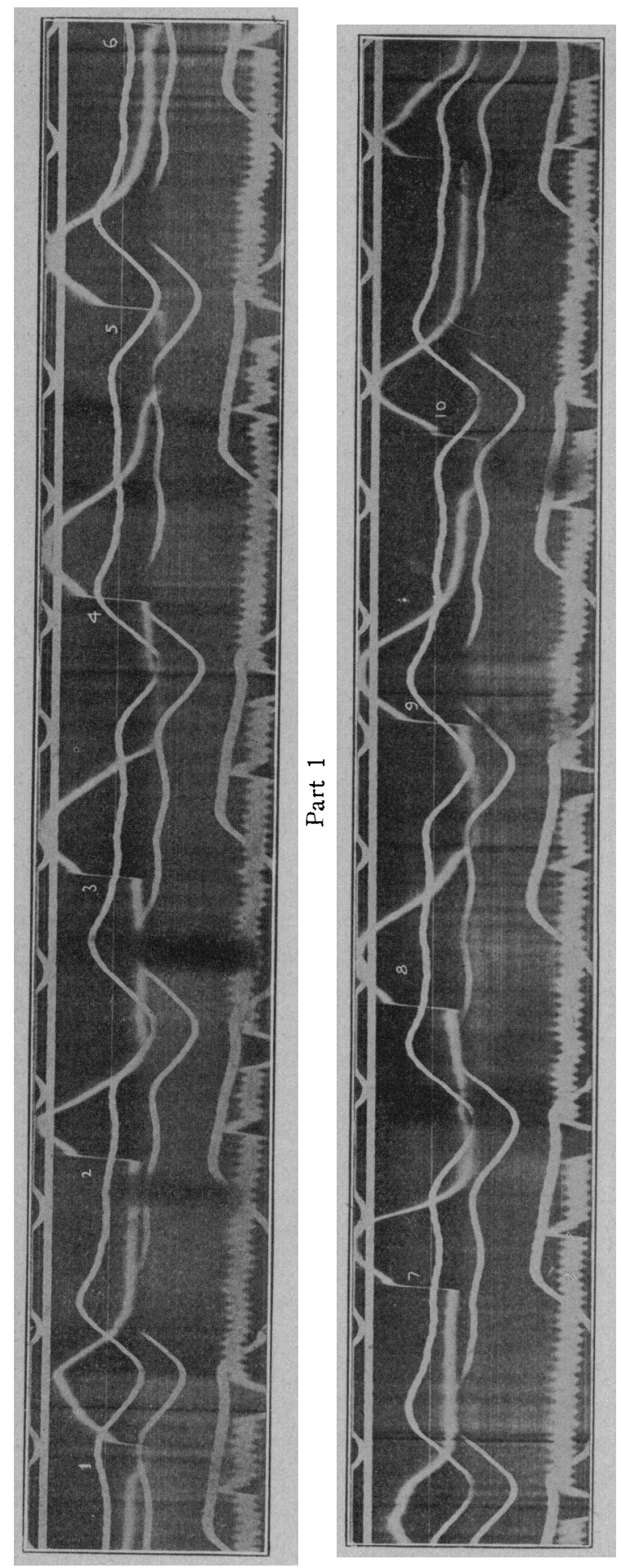

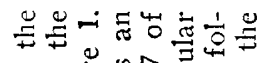

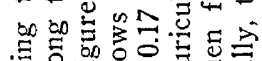

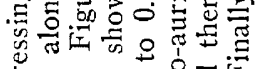

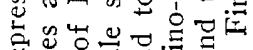

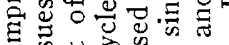

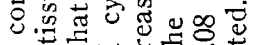

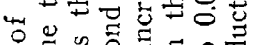
윰.

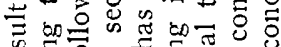

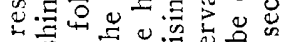

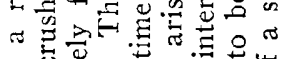
品 $0=0$ क 눙

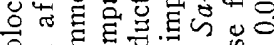
可. E.

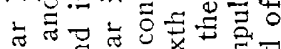

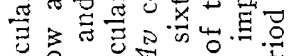

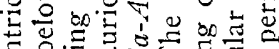

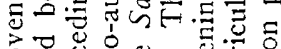

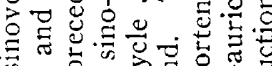

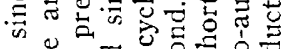
प

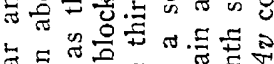

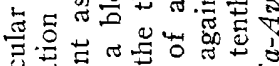
. N त

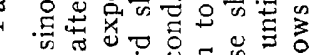

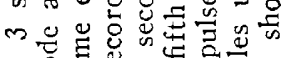

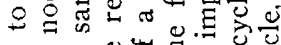
$\checkmark \forall 0$ 马 त.

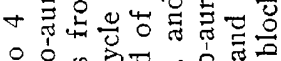

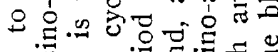

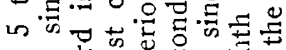

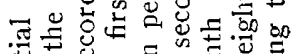

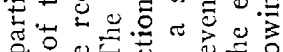
月。 岁出F.

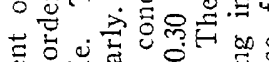

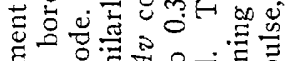

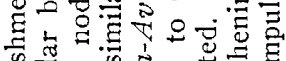
जo

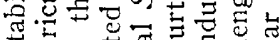

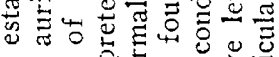

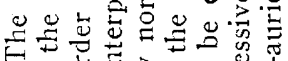
1 on 小 ง

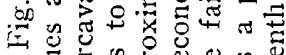

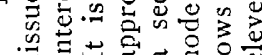


to the normal sinoventricular conduction path, the path between the sino-auricular and auriculoventricular nodes, and the records taken during the above procedure comprised the movements of the galvanometer connected with these two regions along with the records of mechanical systoles. In some of the experiments, finally, suspension records of the right auricle and ventricle were made on smoked paper, in addition to the photographic records.

\section{INCREASE OF SINOVENTRICULAR AND SINO-AURICULAR CONDUCTION TIME AS A RESULT OF PARTIAL ISOLATION OF THE SINO-AURICULAR NODE}

As has been reported in the preceding paper of this series, there is usually a definite increase in the time of conduction from the sinoauricular node to the auriculoventricular node as a result of partial interruption of the paths between these two regions. The normal period may increase from 0.02 or 0.03 of a second to 0.05 of a second. An interesting fact was not infrequently noted in this connection, namely, that the increase in conduction time was usually greater immediately after the interruption than later, a partial return to the normal conduction time usually occurring after a few seconds. Reference may be made to Table 6 of the preceding paper for these data. The time of conduction between the sino-auricular node and the right auricle, the sino-auricular period, was usually unaffected by partial isolation of the node, except along the auricular border. This latter procedure resulted in a definite increase. Finally, it is to be noted that in a number of instances it was possible to have, after the complete abolition of the normal sinoventricular conduction path, the conduction of the excitation from the sino-auricular node to the auriculoventricular by way of the right auricle. Under these circumstances conduction time between the sino-auricular and auriculoventricular nodes was usually considerably prolonged, while sino-auricular conduction time was of normal length or in some cases somewhat diminished. This occurred in only 27 per cent. of all cases; in 73 per cent. conduction to the auriculoventricular node by way of the right auricle was apparently so difficult that auriculoventricular rhythm was at once established when the normal sinoventricular conduction was abolished.

Depression of conductivity in the normal path of conduction between the sino-auricular and auriculoventricular nodes (sinoventricular path) leads therefore at first to increase in this conduction time. Further depression may lead to conduction by an abnormal path, that by way of the right auricle, in about one fifth of all cases, or it may lead to complete blocking of the impulse and the establishment of auriculoventricular rhythm. 


\section{PARTIAL SINO-AURICULAR BLOCK}

Systematic efforts were made to obtain partial sinoventricular block in twenty-one experiments. Summaries of these experiments are given at the end of this paper. Notwithstanding the fact that every experimental factor that we could control was directed toward the production of this condition, it will be seen that in only one case, namely, Experiment 34, was there partial block produced. In a considerable number of the experiments the seat of the pacemaker was shifted several times and at will between the sinoventricular and auriculoventricular nodes, records being constantly made during these transitions. Experiment 19 may serve as an example of cases in which this shifting was produced by clamping, release of clamp, and warming the sino-auricular node. In most cases the records showed that the transition from one type of rhythm to ancther was a sudden

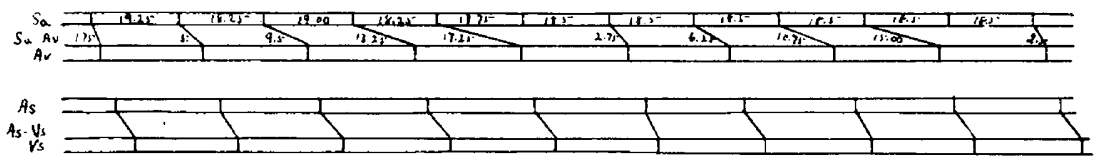

Fig. 3.-Diagrammatic representation of the condition in a similar record to that of Figure 2, showing the relations between the activities in the sinoauricular and auriculoventricular nodes during partial sinus block. The condition shown is that of 6 to 5 and 5 to 4 partial sino-auricular and sinoventricular block. The diagram is drawn to scale from the record and measurements are given in millimeters. In the original record 0.01 of a second $=1.5 \mathrm{~mm}$. In this diagram this is reduced one quarter, so that 0.01 of a second corresponds to $0.375 \mathrm{~mm}$. Sa refers to the onset of the action current in the sinoauricular node, $A v$ the same condition in the ventricular portion of the auriculoventricular node. $S a-A v$ refers to the period of conduction between these two regions. As and $V s$ refer to the onset of the systoles of the right auricle and right ventricle, respectively, and $A s-V s$ to the auriculoventricular intervals.

one, occurring within one or two beats; in others the change was somewhat more gradual. In every case, however, the change was unaccompanied by any evidence of block. So soon as conduction between the sino-auricular and auriculoventricular nodes became sufficiently reduced, the region of lower automaticity assumed at once the pacemaking function. The partial block produced in Experiment 34 was complicated by the fact that the impulse, arising within the sino-auricular node, had been forced, by partial isolation of this node, to pass to the auriculoventricular node and the ventricles by an abnormal path, namely, by way of the right auricle. In this experiment production of interruptions in the normal sinoventricular path, above, below and on the intercaval border of the sino-auricular node forced the impulse to pass to the auriculoventricular node by way of the right auricle. This caused at first a lengthening of the sino-auricular 
node-auriculoventricular node $(S a-A v)$ conduction period from a normal of 0.022 to 0.05 of a second, then the occurrence of auriculoventricular rhythm, and finally the return of sinoventricular rhythm. Later this conduction period was gradually reduced to 0.03 of a second. At this stage of the experiment a clamp was applied along the auricular border of the node and gradually tightened. There was an open space of several millimeters between the clamped area along the auricular border of the node and the ligature that interrupted the path below the node. Gradual tightening of the clamp established the condition shown in the record of Figure 2. This rhythm is clearly that of partial sino-auricular and sinoventricular heart block, in which the sino-auricular node is generating five or six impulses during a period in which only four or five of these are conducted to the auricle. There is a gradual progressive increase of $S a-A v$ conduction until failure of conduction occurs, and one sino-auricular impulse is blocked. Following this, sino-auricular and sinoventricular conduction attains its shortest value, progressively to increase until blocking again occurs. The results from a similar record showing 5 to 4 and 4 to 3 partial block are diagrammed in Figure 3. Screwing down the clamp as tight as possible and interruption of the path in the open space between the clamp and the ligature below the node, by means of another clamp, stopped all conduction from the sino-auricular node and produced auriculoventricular thythm. The degree of partial sinus block was not increased by this procedure, even temporarily; the passage to auriculoventricular rhythm was abrupt.

So far as we have been able to find, this is the first time that absolutely definite proof has been obtained for the possibility of partial sinus block in the mammalian heart. With the exception of certain suspension curves of very doubtful interpretation supposed to show graphically the contraction of the sino-auricular region, ${ }^{7}$ the previous criterion that has been applied to the occurrence of sinus block, both experimentally and clinically, is the dropping of beats in an otherwise regular auricular rhythm or the sudden doubling or halving of the auricular rate. It is noteworthy in this connection that in the one instance of partial sinus block that we have obtained in this series of experiments the suspension curves give absolutely no indication of the condition or indeed suggest any abnormality in rhythm. The true condition is only evident from the relation of the activity of the sinoauricular and auriculoventricular nodes, as registered by the action currents produced in these regions.

Our experiments would seem to establish, in addition to the possibility of sinus block in the mammalian heart, the conclusion that such

7. Rehfish: Arch. f. Anat. u. Physiol., 1906, Supplement, 152. 

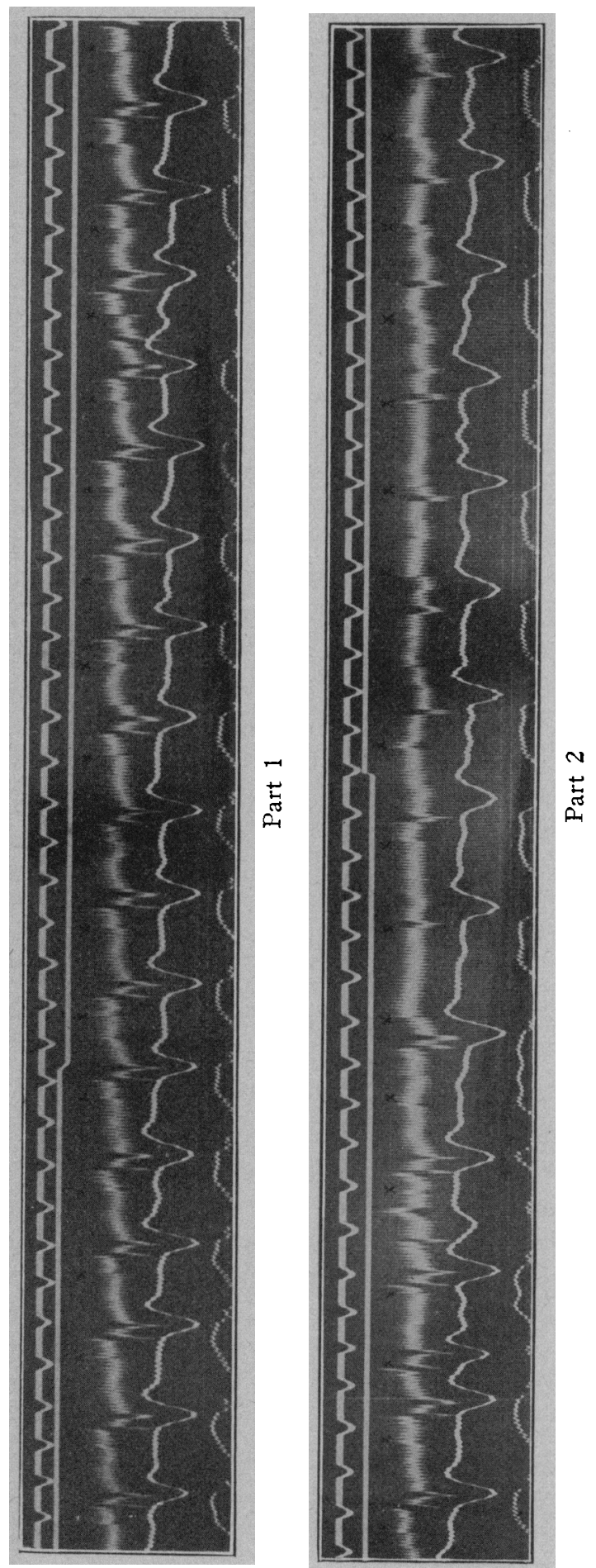

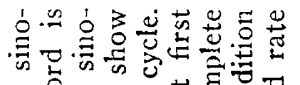

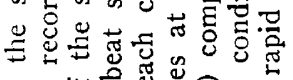

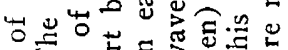

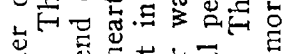

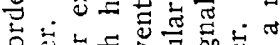

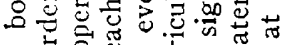

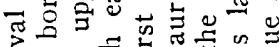

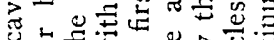

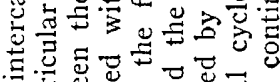

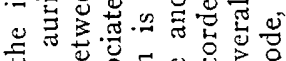
झ

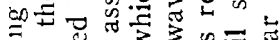

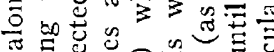

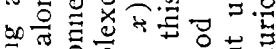

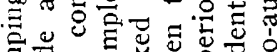

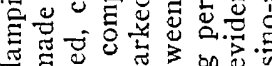

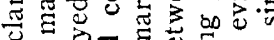
入

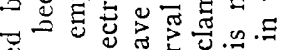

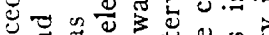

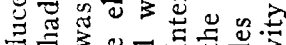

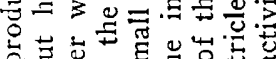

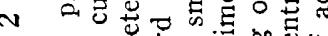

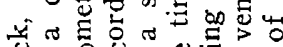
○一 ह है

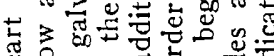

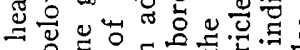

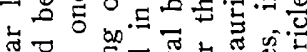

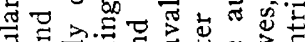

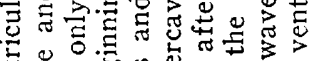

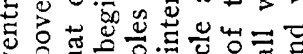

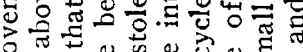

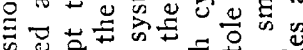

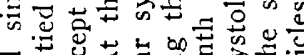

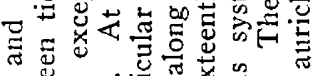
๙

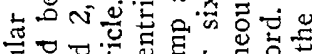

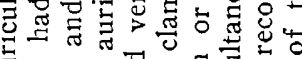

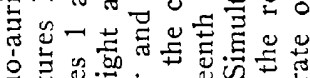

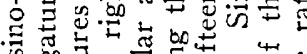

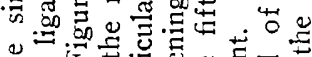

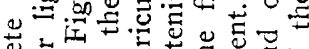

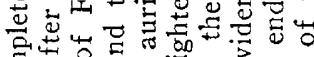
हु유.

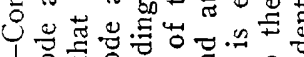
।

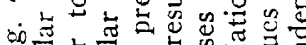

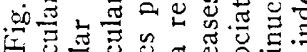

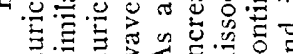


a condition is established only with difficulty. The difficulty of establishment and comparative rarity of partial sino-auricular and sinoventricular heart block in the mammalian heart is particularly striking in comparison with the ease of establishment and frequency of auriculoventricular heart block. While there may be some factors in this connection with which we are unfamiliar or only partially aware of, we believe that our work has given the possibility of a reasonable answer to the question as to the cause of this wide difference in the frequency of establishment of partial sinus block and partial auriculoventricular block. The reason that sinus block is so rarely met with and so difficult to reproduce experimentally we believe to be due to three main factors: (1) the diffuse nature of the path of conduction from the sino-auricular to the auriculoventricular node; (2) the possibility, in a certain percentage of cases, that when the normal sinoventricular conduction path is abolished, conduction between the two nodes may occur by way of the right auricle; (3) the usual relatively small difference between the automaticity of the sino-auricular node and the auriculoventricular node. The nature and position of the normal path of conduction between the sino-auricular and auriculoventricular nodes, the normal conduction of the excitation, arising in the sino-auricular node to the right auricle and to the auriculoventricular node by two separate paths with the possibility of conduction by one path when the other is abolished, and finally the relative automaticity of the two nodes have been discussed in detail in the preceding paper on this series. The diffuse nature of the normal sinoventricular path necessitates a widespread lesion or other influence depressing normal conductivity, in order to interfere with conduction to the point of serious difficulty or abolition. This is in marked contrast to that present in the conductive system between the auriculoventricular node and the ventricles, which occurs for a part of its distance over a very restricted path, the auriculoventricular bundle. The most important factor tending to prevent the occurrence of partia! sinoventricular block is, however, the relatively high automaticity of the auriculoventricular node in the mammalian heart. In thirty-four cxperiments, reported in the preceding paper of this series, in which auriculoventricular rhythm developed as a result of eliminating sinoventricular conduction, the auriculoventricular node discharged at a rate equal to an average of 67 per cent. of the original sino-auricular discharge. In other words, in the average dog's heart the auriculoventricular node may be regarded as possessing an inherent automaticity equal to 67 per cent. of the automaticity of the sino-auricular 
node. ${ }^{8}$ It is evident that if the condition of depressed conductivity between the sino-auricular and auriculoventricular nodes developed to the point at which every other or even every third impulse arising in the former node would be blocked, the automaticity of the auriculoventricular node would at once become dominant and auriculoventricular rhythm appear. In the average dog's neart, therefore, the relations of automaticity between the two nodes are such that a partial sino-auricular block of greater degree than that represented by the blocking of every third or fourth impulse from the sino-auricular node would be impossible. Two to one partial blork would be possible only in these cases in which the automaticity of the auriculoventricular node was less than half that of the sino-auricular node. This condition was not met with in the thirty-five experiments mentioned above nor in any of the experiments of the present series.

It seems evident, therefore, in order for sino-auricular block of a type approaching that seen in auriculoventricular block, a 2 to 1 or even a 3 to 2 block, to develop, at least two conditions must be present: (1) a degree of depression in the sinoventricular conducting path of exactly the right amount to block every other or every third sinoauricular impulse and no more; and (2) a greater difference in automaticity between the sino-auricular and auriculoventricular node than the average or indeed that which seems normally to exist. It seems probable that in any case in addition to the depression in conductivity there must be a depression also of the normal automaticity of the auriculoventricular node.

The previously reported cases of supposed clinical and experimental sino-auriculo heart block, we believe, show certain interesting features in this connection. Of the nine clinical cases in which the absence of beats in an otherwise regular auricular rhythm were satisfactorily determined ${ }^{9}$ in only one was the condition ever such as to lead to the interpretation of a condition of a partial sino-auricular block in which more than every other impulse was blocked (2 to 1 sino-auricular block). In this case (Case 2 of Levine) pauses equal to as long as five normal heart cycles were encountered. It is significant in this case, however, that at times, as a result of prolonged blocking of the sinus impulses, the heart began beating, not in auriculoventricular rhythm, but with an independent ventricular (idioventricular) rhythm. It is fair to conclude, therefore, in this case that the automaticity of the auriculoventricular node was much depressed or

8. Certain experiments which we have performed on the cat's heart, and which will be reported subsequently, indicate an even closer relation between the automaticity of the sino-auricular and auriculoventricular node (particularly the auricular portion or coronary sinus region) in these animals than. in the dog.

9. Eyster and Evans: Footnote 3, second reference. Levine: Footnote 4. 
abolished. The usual type of sino-auricular block that has been reported clinically in man consists of occasional dropped beats. In the case reported by Eyster and Evans, ${ }^{10} 2$ to 1 block was observed occasionally, never a greater degree. Auriculoventricular rhythm developed at times. The rate of discharge in this latter rhythm was evidently such as to prevent the development of a greater degree of partial block. In at least five of the clinical cases that have been reported the condition of block developed only after the administration of digitalis. The presumption in these cases is that the block developed as a result of depression of conductivity induced by this drug. In the case of Eyster and Evans, in which block occurred independently of digitalis administration, there was abundant evidence that the condition was associated with a hypervagotonus.

Of the previously reported probable instances of experimental sinoauricular block, that of Cushny ${ }^{11}$ following the administration of aconitin and that of Eyster and $\mathrm{Meek}^{3}$ resulting from large doses of morphin were undoubtedly the result of the action of these substances on the vagal mechanism, and one can readily assume, along with the depression of conductivity, a depression of automaticity of the lower automatic regions. Possibly these substances produce block by a certain degree of selective action on these parts. There is no evidence that stimulation of the vagus mechanism by the usual experimental methods ever produces this result. In Cushny's experiments the evidence pointed to 2 to 1 partial block. In the experiments with morphin the usual type was 2 to 1 , but a rhythm interpreted as 3 , to 1 block occurred at times. Independent ventricular beats of idioventricular type occurred after prolonged blocking of the sinus impulse, a further indication of the depression of the normal degree of automaticity of the auriculoventricular node.

We feel that it is clear, therefore, that two conditions must be fulfilled in order for a degree of sinoventricular or sino-auricular block greater than the occasional blocking of an impulse to develop in the mammalian heart: (1) a widespread disturbance in conductivity in the regions surrounding the sino-auricular node, and (2) a depression of the inherent automaticity of the auriculoventricular node below its usual value. The infrequency of the fulfilment of those two conditions, we believe, explains the comparative rarity of this condition clinically and the difficulty of its attainment experimentally. The conditions are in marked contrast to those present in the auriculoventricular conductive system. Here the conductive path in a part of its course is markedly circumscribed, and great differences exist between the automaticity of the sino-auricular node or even the auriculoventricular

10. Eyster and Evans: Footnote 3, second reference.

11. Cushny: Heart, 1910, 1, 1. 

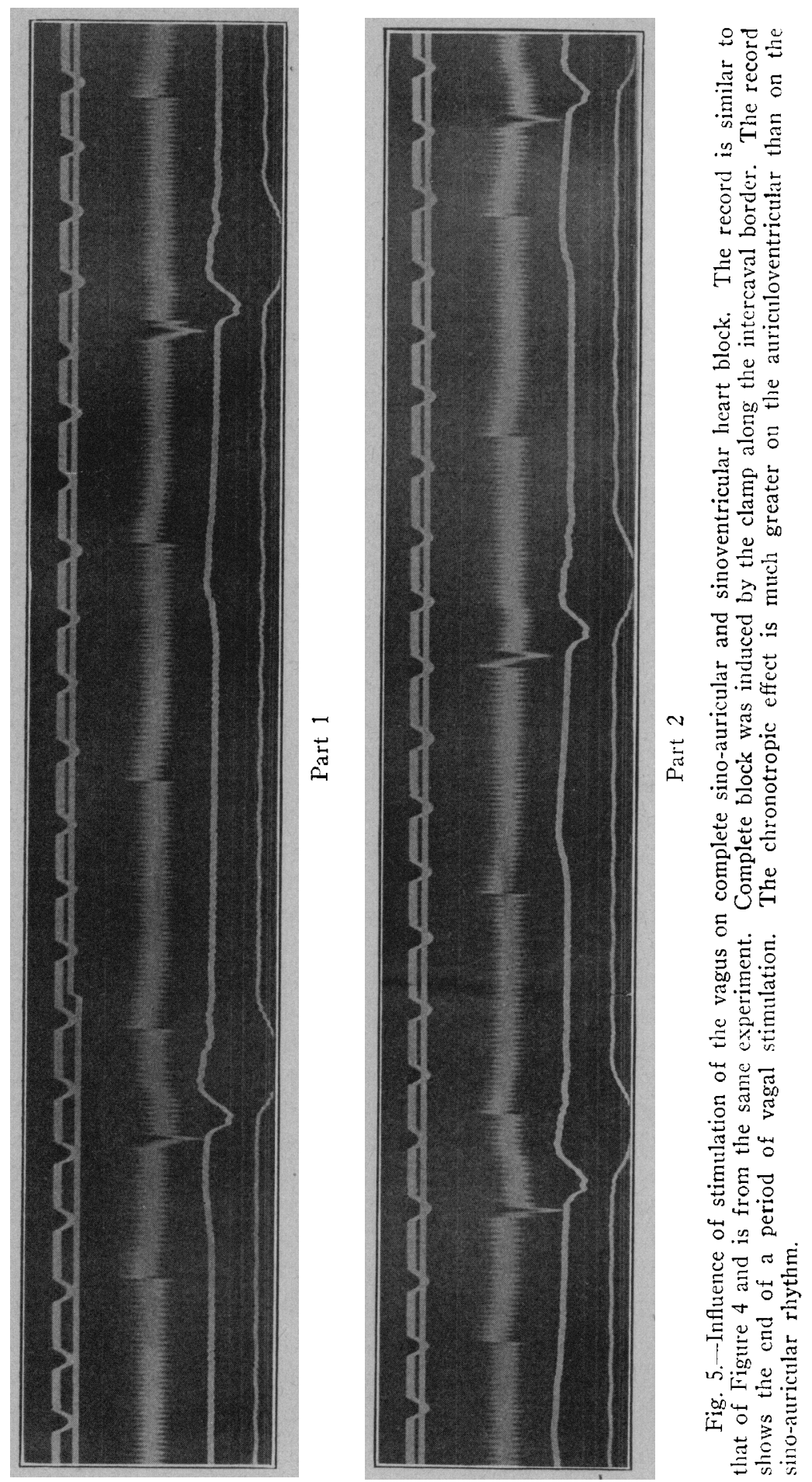
node and the automatic or idioventricular centers. Exact figures for the rate of discharge in idioventricular thythm in the dog's heart compared with the normal sino-auricular rhythm are unavailable, but it is certainly less than half. The ventricle in complete auriculoventricular heart block in man rarely beats at a rate greater than 30 per minute and frequently as low as 15 to 20 beats per minute. or from one-third to one-fourth the normal sinus rate.

Experiments reported previously by $\mathrm{us}^{12}$ have led us to the conclusion that while normally the excitation spreads from its origin in the sino-auricular node directly to the right auricle and by a separate and diffuse path to the auriculoventricular node, two other possible paths may be employed. Interruption of the normal sinoventricular path leads to the spread of the excitation from the sino-auricular node to the auriculoventricular node by way of the right auricle in about 27 per cent. of all cases. In these instances the sino-auricular and sinoventricular paths are in part common paths. In the remainder auriculoventricular rhythm develops. Interruption of the normal sinoauricular path does not abolish the reception of excitations by the auricle. Under those circumstances, if the sinoventricular conduction path is intact, it receives its excitations apparently by way of some part of this path, or perhaps from some part of the auriculoventricular node. According to this interpretation, partial sino-auricular block is impossible when the natural sinoventricular path is intact, and for this we have abundant experimental evidence. In a number of experiments gradual clamping of the direct auricular connections of the sino-auricular node has been carried out without evidence of block. Complete interruption of these connections leads to an increase in sino-auricular conduction time, evidence of the more circuitous route taken by the impulse, but each impulse arising from the sino-auricular node reaches the auricle. Likewise, sinoventricular block, partial or complete, as a result of interruption of the normal sinoventricular path alone, is impossible in those cases (about 27 per cent.) in which the possibility of conduction to the auriculoventricular node by way of the right auricle is present. In the remainder partial sinoventricular block, independent of sino-auricular block, is conceivable and should be obtained experimentally if a sufficient number of careful attempts are made.

COMPLETE SINO-AURICULAR BLOCK

Interference with the conduction in the sinoventricular path to the point of its abolition leads to conduction to the auriculoventricular node by way of the right auricle or, as occurs more frequently, the assumption of dominance in automaticity by the auriculoventricular

12. Eyster, J. A. E., and Meek, W. J.: Footnote 5; Heart, 1914, 5, 119. 
node anr. the occurrence of auriculoventricular rhythm. In these cases in which conduction to the auriculoventricular node persists by way of the right auricle, auriculoventricular rhythm is in all cases produced finally by interruption of this conduction path. Every case of auriculoventricular rhythm produced by abolition of the sinoventricular conduction paths may be considered as potentially one of complete sinoventricular heart block. Whether this condition can be actually constituted depends on whether one can prove that the sino-auricular node continues in activity under those circumstances. This we have succeeded in doing in two of the cases of auriculoventricular rhythm occurring in the experiments reported in this paper (Experiments 20 and 25 ). In the remainder there has been no evidence obtainable that the sino-auricular node continues to discharge when its function as pacemaker for the heart has been taken over by a region of lower

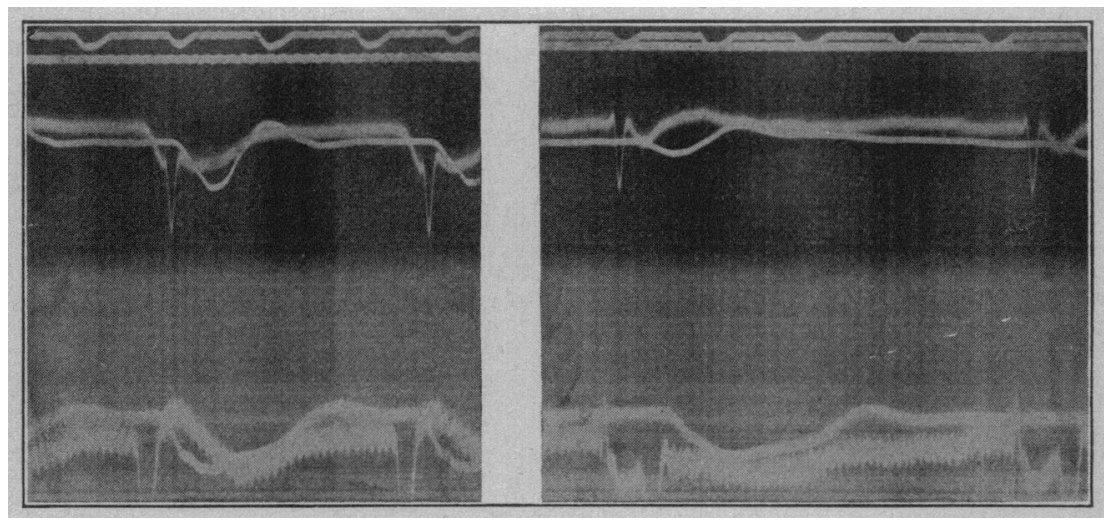

Fig. 6.- Vagal stimulation during auriculoventricular rhythm may lengthen the $A s-V s$ interval without causing a return of the pacemaker to the sinoauricular node. The records are to be interpreted as Figures 1 and 2. The left part of the illustration shows the condition before, and the right, during stimulation of the right vagus nerve.

automaticity. These two instances demonstrate for the first time, however, the experimental possibility of complete sinoventricular block, that condition in which the sino-auricular node continues to generate impulses at approximately its normal rate and at a faster rate than the other region which is acting as the seat of origin of the heart beat. The excitations, arising within the sino-auricular node, exert no influence because of the interruption of the conduction paths connecting this region with the other parts of the heart (Figs. 4 and 5).

When the normal path of conduction from the sino-auricular node to the right auricle is abolished, the right auricle may continue to receive impulses from the node by way of the sinoventricular path, as described above. Interruption of the direct auricular connections 
of the right auricle with the sino-auricular node results, therefore, not in sino-auricular block, as might be expected, but with merely a delay in conduction time from the node to the auricle.

Theoretically, one might obtain partial or complete sinoventricular block with normal sino-auricular conduction. In these cases in which conduction of the excitation from the sino-auricular node to the auriculoventricular node by way of the right auricle is impossible, and in which, therefore, interruption of the normal sinoventricular path results in auriculoventricular rhythm, it is conceivable that the right auricle might continue to receive its excitations from the sino-auricular node and thus beat at a faster rate than the remainder of the heart. This condition we have never met with, however, in any of our experiments.

\section{SUMMARY}

1. The possibility of partial and complete sinoventricular heart block has been constituted in the mammalian heart by independent registration of the activities of the sino-auricular node, right auricle and auriculoventricular node by means of the action currents produced in these regions.

2. Since normally conduction from the sino-auricular node to the right auricle and to the auriculoventricular node and ventricular conductive system occurs by two separate paths, a sino-auricular path and sinoventricular path, possibilities of block in either path must be considered. In a certain percentage of experiments it has been found that abolition of the sinoventricular path results in utilization of the sino-auricular path for conduction to the auriculoventricular node. The single case of partial block described in this joper was concerned with depression of conduction in this path and was therefore combined sinoventricular and sino-auricular block.

3. It is believed that there are two important factors which tend to prevent the establishment of partial sinoventricular block and which render it so difficult to obtain experimentally and explain its extreme rarity as a clinical condition. These are the diffuse nature of the path concerned in sinoventricular conduction and the relatively high automaticity of the auriculoventricular node. This latter region is probably always more than half as automatic as the sino-auricular node. The establishment of partial sinoventricular block of a grade equal to or greater than that of a 2 to 1 relation requires, therefore, the simultaneous operation of two factors, a depression of conductivity in the sinoventricular path of a certain definite degree, and a depression of the normal automaticity of the auriculoventricular node without any depression or with a less degree of depression of the sino-auricular node. 
4. Complete sinoventricular block is a possible condition whenever auriculoventricular rhythm develops as the result of abolition of the sinoventricular conduction path. If the sino-auricular node continues under these conditions at its normal rate or at a faster rate than the remainder of the heart, the condition is one of complete sinoventricular block. We have been able to obtain this condition in two of the cases of auriculoventricular rhythm resulting in those experiments from abolition of the sinoventricular conduction path.

\section{SUMMARIES OF EXPERIMENTS}

EXPERIMENT 1.-Electrocardiograms were made throughout the experimental procedures from Lead II. Torsion on exposed sino-auricular node by means of fine-pointed forceps produced shortening of $P R$ interval. The gradual clamping of nodal tissue produced fusion of the $P$ and $R$ waves. There was no evidence of partial block at any time.

Experiment 2.-Electrocardiograms were made from Lead II. Suspension curves of right auricle and right ventricle. The upper portion of sino-auricular node was caught in blunt forceps and submitted to torsion and twisting. There were numerous extrasystoles, but no evidence of block. Clamping the node produced coronary sinus rhythm, as indicated by the shortening of the $A s-V s$ interval, lengthening of the cycle, and so confirmed by the determination of the point of initial negativity.

Experiment 3.-Electrocardiograms were made from Lead II. Comparisons were made to determine the seat of initial negativity and the relation of negativity in different regions to mechanical systole of the right auricle. Suspension curves of right auricle and right ventricle. The gradual clamping of the sino-auricular node with a specially devised clamp produced auriculoventricular rhythm with $A s-V s=O ; P$ and $R$ fused. There was recovery of the normal rhythm on loosening the clamp. There was no evidence of partial block on passage into or recovery from auriculoventricular rhythm.

ExpERIMENT 4,-This was similar in every way to the last experiment. The clamping produced coronary sinus rhythm. There was no evidence of block.

EXPERIMENT 5.-This was similar to the last experiment. Clamping of the sino-auricular tissue produced numerous extrasystoles, an attack of auricular flutter, and finally recovery with heart in coronary sinus rhythm. There was no evidence of block.

EXPERIMENT 6.-This experiment was similar to the last, except that 10 per cent. cocain solution was applied to the sino-auricular node. This resulted in passage into auriculoventricular rhythm without evidence of block.

Experiment 7.-This was similar to the last experiment. Several applications of 10 per cent. and 20 per cent. cocain solution caused at first temporary slowing of the sino-auricular rhythm without a change in the seat of the pacemaker. Later, a period of auriculoventricular rhythm resulted with subsequent recovery of normal sino-auricular rhythm. There was no evidence of partial block at any time.

EXPERIMENT 8.-This was similar to the last experiment. Various strengths of nicotin applied to the sino-auricular node, namely, 1, 5, and 10 per cent., produced slight slowing of the sino-auricular rhythm without change in the seat of the pacemaker. Twenty-five per cent. caused transitory auriculoventricular rhythm with each application. There was no evidence of partial block.

EXPERIMENT 9.-This was similar to the last experiment. Weaker strengths of nicotin produced slowing of the sino-auricular rhythm. Transitory periods of coronary sinus rhythm were caused by 25 per cent. nicotin. There was no evidence of block at any time. 
In most of the following experiments two galvanometers were employed with measurements of relative time of onset of negativity in different regions and changes in these relations during and following partial or complete isolation of the sino-auricular node.

Experiment 10.-Normally $S a-R a=0.016, S a-A v=0.028, A s-V s=0.095$, cycle $=0.38$. Tying a ligature across the sulcus terminalis below the node produced no change with the exception of several extrasystoles during the act of tying. Tying the ligature along the venous border of the sulcus produced an auriculoventricular rhythm lasting for about ten minutes, with $A v-S a=$ $0.015, A s-V s=0.03$, cycle $=0.44$. Sino-auricular thythm returned with $S a-A v=$ $0.04, S a-R a=0.02, A s-V s=0.07$, cycle, 0.41 . There was no evidence of partial block during the tying of the ligatures or during the period of recovery of sino-auricular rhythm.

Experiment 11. - Normally $S a-R a=0.03, S a-A v=0.012, A s-V s=0.08$, cycle $=0.33$. A ligature was tied across the sulcus below the node. This produced transitory coronary sinus rhythm $(S a-A v=0.005)$, with return of sino-auricular rhythm within one minute. $S a-A v=0.023, A s-V s=0.09$, cycle $=$ 0.35 . Tying a ligature along approximately the lower half of the intercaval border of the sulcus produced coronary sinus rhythm, with $S a-A v=0.005$, $A s-V s=0.06$, cycle $=0.38$. This rhythm was confirmed by direct comparisons of onset of negativity. Transition to this rhythm occurs within one beat without evidence of block. Coronary sinus rhythm persisted for about thirty minutes, when sino-auricular rhythm returned with $S a-A v=0.035, A s-V s=$ 0.08 , cycle $=0.38$.

Experiment 12. - Normally $S a-R a=0.011, S a-A v=0.026, \quad A s-V s=0.11$, cycle $=0.33$. A ligature was tied along the intercaval border approximately the lower half of the sulcus. This caused a shift of the pacemaker from the upper to the lower end of the sino-auricular node. $S a-A v=0.008, A s-V s=$ 0.08 , cycle $=0.42$. A ligature was tied across the sulcus below the sino-auricular node. This produced auriculoventricular rhythm: $A v-S a=0.025, A s-V s=0.04$, cycle $=0.47$. The record taken during the tying of this ligature shows no evidence of partial block. Later $A v-S a=0.025, A s-V s=0.05$, cycle $=0.48$.

Experiment 13.-Normally $S a-A v=0.028, A s-V s=0.12$, cycle $=0.27$. Two ligatures along the intercaval borders of the sulcus, together extending the full length of the node, produced no effect. Ligation across the sulcus below the node lengthened $S a-A v$ to 0.034 . $A s-V s$ and cycle remained unchanged. Ligation across the sulcus above the node produced auriculoventricular rhythm of the coronary sinus type. $A v-S a=0.003, A s-V s=0.08$, cycle $=0.33$. The record taken during the development of this rhythm shows no evidence of partial block.

EXPERIMENT 14. - Normally $S a-A v=0.026, \quad S a-R a=0.02, \quad A s-V s=0.10$, cycle $=0.43$. A cut was made along the auricular border of the sulcus. There was no change except $S a-R a$ lengthens to 0.026 . A cut made across the sulcus below the node produced no further change. A cut along the intercaval borders of the sulcus produced auriculoventricular rhythm, with $A v-S a=0.022$, $. t s-V s=0$, cycle $=0.68$. The records were made only after the interruptions were completed.

Experiment 15. - Normally $S a-A v=0.022, \quad S a-R a=0.013, \quad A s-V s=0.08$, cycle $=0.29$. A cut was made along the auricular border of the sulcus; $S a-R a$ increased to 0.02 , with no further change. A cut made along the intercaval border of the sulcus produced auriculoventricular rhythm with $A v-S a=0.026, V s-A s=0.03$, cycle $=0.40$. The records were made only after the interruptions were completed. 
Experiment $16 .-$ Normally $S a-A v=0.03, \quad S a-R a=0.014, \quad A s-V s=0.10$, cycle $=0.42$. A cut was made along the auricular border of the sulcus; $S a-R a$ increased to 0.028 , with no further change. A cut was made along the intercaval border of the sulcus; the pacemaker removed to the lower end of the sino-auricular node; $A s-V s=0.09$, cycle $=0.47$. A ligature was tied across below the sulcus, Auriculoventricular was established, with $A v-S a=0.019$, $A s-V s=0.07$, cycle $=0.48$. There was no evidence of partial block before or during the establishment of this rhythm.

ExPERIMENT 17.-Normally $S a-A v=0.024, S a-R a=0.016$, cycle $=0.30 . \quad$ A cut was made along the intercaval border of the sulcus, with no change. A ligature was tied across the sulcus above the node, with no change. Ligatures were tied across the sulcus below the node. The first of these caused no change; the second produced auriculoventricular rhythm, with $A v-S a=0.031$, $A v-R a=0.038, A s-V s=0$, cycle $=0.36$. No evidence of block in passage into this rhythm.

EXPERIMENT 18. - Normally $S a-A v=0.035, \quad S a-R a=0.03, \quad A s-V s=0.14$, cycle $=0.29$. A cut was made along the upper half of the intercaval border of the sulcus. There was a transitory period of coronary sinus rhythm with $S a-A v=0, A s-V s=0.09$, cycle $=0.33$. Later there was a return to normal rhythm. A cut was made along the lower half of the intercaval border of the sulcus, with no change. A ligature tied across the sulcus below the node produced auriculoventricular rhythm with $A v-S a=0.031, A v-R a=0.047$, $A s-V s=0.04$, cycle $=0.37$. There was no evidence of block in the development of this rhythm.

EXPERIMENT 19.-In this experiment galvanometer records were made only at times to determine with certainty the position of the pacemaker. Frequent records were made of the systole of the right auricle and ventricle on a Hürthle kymographion. Ligatures were laid across the sulcus above and below the node. The upper one was tied without result; the lower one produced auriculoventricular rhythm. The $A s-V s$ interval shortened from 0.11 to 0.03 ; the cycle lengthened from 0.38 to 0.47 . This ligature was now removed and normal rhythm returned, with $A s-V s=0.12$, cycle $=0.38$.

With the ligature above the node remaining tied, the lower ligature was removed and a clamp was inserted along the intercaval borders of the sulcus. Putting it in position produced no effect, nor did screwing it down tight. The clamp was now loosened and the ligature laid and tied across the sulcus below the node. This produced auriculoventricular rhythm with recovery of sinoauricular rhythm after removal. Later auriculoventricular rhythm was again established. Sino-auricular rhythm returned on application of warmth to the head of the sino-auricular node. This rhythm remained after tying the ligature again below the node, but auriculoventricular rhythm resulted when the clamp along the intercaval border was tightened. Loosening the clamp, removing upper and lower ligatures and warming the node resulted in a return of sino-auricular rhythm. Auriculoventricular rhythm was again produced by replacing the ligatures and gradually tightening the clamp. Finally, application of heat to the node caused return of sino-auricular rhythm, with ligatures and clamp in place. Transitory auriculoventricular rhythm with recovery was now produced several times and at will by traction on one or the other of the ligatures. Records were taken throughout the above procedures. Usually the transition from sino-auricular to auriculoventricular rhythm occurs within one beat, in other cases the changes were gradual. None of the records give any indication whatever of partial block at any time.

EXPERIMENT 20.-This experiment is similar as to the procedures carried out and the results obtained as the last, except that the condition of complete sino-auricular block during the periods of auriculoventricular rhythm was 
proved. A cut was first made along the auricular border of the sulcus. This was without effect. Ligatures were tied across above and below the node without change. A clamp was now placed along the intercaval border, connecting the ligatures above and below and gradually tightened. Auriculoventricular thythm resulted. The $A s-V s$ interval shortened from 0.12 of a second to 0 . The cycle lengthened from 0.40 to 0.53 . On loosening the clamp sinoauricular rhythm returned. The transition from sino-auricular to auriculoventricular rhythm was abrupt, within one beat. Following the normal cycles of 0.40 , there occurred a pause of 0.67 of a second and auriculoventricular rhythm set in at once with $A s-V s$ of 0 , cycle of 0.53 . The production of and recovery from auriculo-ventricular rhythm was brought about several times by tightening and loosening the clamp. Later, after loosening the clamp, auriculoventricular rhythm continued.

Stimulation of the right vagus nerve in this condition produced a transitory return of sino-auricular rhythm lasting for seven cycles, then return of auriculoventricular rhythm. The inotropic effect of the vagus on the auricle made it evident visually that the region of the sino-auricular node was beating at a much faster rate than the auricles or ventricles, and that we were dealing either with a definite partial or complete sino-auricular heart block. Electrodes were therefore placed in the usual position and the above procedures duplicated. These records show (Figs. 4 and 5), reading from top to bottom, (1) time in one-fifth second intervals; (2) signal pen; (3) galvanometer thread connected to electrodes on sino-auricular node and right auricle; upward movement of the curve indicating negativity in the node; (4) systoles of the right auricle, and (5) right ventricle, the systole being indicated by down strokes in each case. Figure 4 shows the transition from sino-auricular rhythm to auriculoventricular rhythm with complete sinoventricular block, as a result of tightening the clamp along the intercaval border. The transition occurs within one cycle. It is evident that the sino-auricular node is giving evidence of its activity here independently of the activity of any other part of the heart. The normal cycle length averages 0.42 of a second and the sino-auricular node continues to discharge at this rate during the auriculoventricular rhythm. The rate of discharge of the auriculoventricular node, which is now acting as pacemaker for the heart, is given by a cycle length averaging 0.55 of a second.

Figure 5 shows the effect of vagus stimulation. The clamp was tightened just enough to produce auriculoventricular thythm before this procedure. The sino-auricular rate of discharge before the vagus stimulation was indicated by a cycle length of 0.44 of a second. The auriculoventricular node discharged at intervals of 0.54 of a second. During the vagus stimulation there was a greater depressing effect evident on the discharge of the auriculoventricular than on the sino-auricular node, due, no doubt, to the fact that the ligatures and clamp had interfered with a part of the connections of the latter with the nerve. There is no definite relation between the sinoventricular and auriculoventricular impulses, during or before the stimulation, and the condition is evidently one of complete block. ${ }^{13}$ The above procedures were repeated several times: normal sino-auricular rhythm, production of auriculoventricular rhythm by gradually clamping, the influence of vagus stimulation, and finally the return of sino-auricular rhythm as a result of loosening the clamp. At no time was there any evidence of partial block.

13. It may be noted that in this and in subsequent periods of vagus stimulation, while auriculoventricular rhythm and complete sinoventricular and sinoauricular block persisted, the auriculoventricular interval lengthened from 0 to an average of about 0.08 of a second. Lengthening of the $A s-V s$ interval on vagus stimulation during auriculoventricular rhythm does not necessarily mean, therefore, the return of sino-auricular rhythm, as has been generally assumed. A further example of this is given in Figure 6. 
Experiment 21.-This experiment was similar to the last. A cut was made along the auricular border of sulcus, ligatures were applied above and below the sino-auricular node, and a clamp along the intercaval border of the sulcus. Coronary sinus rhythm was produced by tightening the clamp. The galvanometer records showed no indication of activity of the sino-auricular node independent of that of the coronary sinus region. The apparently dropped beats observed in the records of the mechanical systoles were shown by the galvanometer records to be pauses following extrasystoles.

EXPERIMENT 22.-Cuts were made along the auricular border of the sulcus and across the sulcus above and below the sino-auricular node without producing loss of function of the node as pacemaker. A clamp was now applied along the intercaval borders of the sulcus and was gradually tightened. The records made during this procedure showed no change until the sudden occurrence of auriculoventricular rhythm. $A s-V s$ shortened from 0.08 to 0 ; the cycle lengthened from 0.40 to 0.50 . There was no indication of partial block. The galvanometer records show no indication of activity of the sino-auricular node independent of the auriculoventricular node during the auriculoventricular rhythm.

EXPERIMENT 23.-Cuts along the auricular border of the sulcus, above and below the node, caused no change in the pacemaker. Clamping along the intercaval border of the sulcus produced auriculoventricular rhythm. Normal rhythm returned on loosening the clamp and warming the sino-auricular node. Auriculoventricular rhythm was produced by again tightening the clamp. The sinoauricular rhythm was restored by loosening the clamp and warming the node or by mild vagal stimulation. These experiences were repeated a number of times with records made during all procedures. There was no indication at any time of partial sino-auricular block.

EXPERIMENT 24.--This was practically identical in procedures and results to the last experiment.

EXPERIMENT 24.-This was practically identical in procedures and results conclusively that complete sinoventricular and sino-auricular block may be associated with auriculoventricular rhythm. Auriculoventricular rhythm was produced by a cut along the auricular border of the sulcus and ligatures above and below the node. Tying permanently one of these ligatures and traction on the other was sufficient to cause auriculoventricular rhythm to develop, sino-auricular rhythm returning on cessation of the traction. Galvanometer records showed an independent and more rapid discharge of the sino-auricular node during the periods of auriculoventricular rhythm. Numerous records made during the transition from one type of rhythm to the other showed no evidence at any time of partial block. During the auriculoventricular rhythm, vagus stimulation caused a greater slowing of the discharge from the auriculoventricular than the sino-auricular node.

EXPERIMENT 26.-The coronary sinus rhythm was produced by a cut along the auricular border, ligatures above and below the node and clamping along the intercaval border of the sulcus.

EXPERIMENT 27.-This was similar to last experiment. The coronary sinus rhythm was produced by a cut along the auricular border and ligatures above and below the node.

EXPERIMENT 28.-This was similar to last experiment. The auriculoventricular rhythm was produced by ligatures above and below the node and clamping along the intercaval border.

EXPERIMENT 29.-Tying a ligature above the node caused a lengthening of the $S a-A v$ conduction time from 0.019 to 0.023 . After four cycles there were six cycles of auriculoventricular rhythm in which $A v-S a=0.007$ of a second. 
and during which $A s-V s$ shortened progressively from 0.11 to 0.02 of a second. These were followed by a sudden return of sino-auricular rhythm with $S a-A v=$ 0.04 of a second, and a gradual lengthening of $A s-V s$. The change in the seat of the pacemaker occurred within one beat, while the $A s-V s$ shortened gradually and also returned only gradually to its normal length on the restoration of sino-auricular rhythm. Tying the ligature across the sulcus below the node produced permanent auriculoventricular rhythm with $A s-V s=0$. The cycle lengthened from 0.32 to 0.39 of a second. $A v-S a=0.036$ of a second. Vagus stimulation was without influence until the two ligatures were removed, when a transitory period of return of sino-auricular rhythm occurred, with $S a-A v=0.05, A s-V s=0.08$ of a second. There was no evidence of partial block during the transitions from one type of rhythm to the other.

ExPERIMENT 30 - Normally $S a-A v=0.031, A s-V s=0.19$, cycle $=0.35$ of a second. A ligature was laid across the sulcus above the sino-auricular node. The first cycle after tying this ligature is an auricular extrasystole. The third cycle shows $S a-A v=0.035$, while $A s-V s$ has shortened to 0.027 of a second. The fourth cycle shows the same $S a-A v$, while $A s-V s$ has become zero. The fifth cycle shows $A v-S a=0.032, A s-V s=0$. The sixth to the thirteenth cycles show $A v-S a=0.064, V s-A s=0.023$. The fourteenth cycle is an ectopic ventricular beat. The fifteenth cycle shows $S a$ and $A v$ simultaneous, $A s$ and $V s$ simultaneous. The sixteenth cycle after the ligature was tied shows $S a-A v=$ $0.04, A s-V s=0$. In the succeeding cycles, $S a-A v$ remains about the same, $A s-V s$ gradually lengthens through succeeding cycles to $0.014,0.051,0.086$, $0.125,0.150,0.160,0.166$ of a second. The twenty-fifth cycle after the ligature was tied shows $S a-A v=0.05, A s-V s=0.17$ of a second.

Ligaturing across the sulcus above the head of the node thus produced transitory auriculoventricular rhythm lasting for fourteen cycles, with return to sino-auricular rhythm with increased $S a-A v$ conduction time. In the transition into auriculoventricular rhythm the change from $S a-A v$ to $A v-S a$ was abrupt, the change in $A s-V s$ more gradual. This is even more marked during the return to normal sino-auricular rhythm. Here the change from $A v-S a$ to $S a-A v$ occurred within two cycles, while $A s-V s$ showed a gradual and progressive increase extending over seven cycles.

Ligaturing across the sulcus below the node caused no change except a moderate shortening of $A s-V s$. After this ligature was tied, $S a-A v=0.05$, $A s w s=0.13$, cycle $=0.38$. Clamping along the intercaval border of the sulcus caused no further change.

Experiment 31.-Normally $S a-A v=0.014, A s-V s=0.09$, cycle $=0.41$. Ligation above the head of the sino-auricular node produced transitory auriculoventricular rhythm with changes similar to those described in the last experiment.

EXPERIMENT 32.-The changes in $S a-A v$ during the establishment of transitory auriculoventricular rhythm as a result of ligation above the sinoauricular node differ from those in Experiment 30, in that they occur gradually and not abruptly. These changes in successive cycles subsequent to the ligation are as follows: $S a-A v=0.010,0.007,0.006,0.005 ; A v-S a=0.004,0.007$, $0.014,0.010,0.010,0.010,0.006,0.000 ; A s-V s=0.090,0.073,0.072,0.073,0.060$, $0.058,0.057,0.063,0.063,0.063,0.068,0.078 ; S a-A v=0.015,0.017,0.020 ; A s-V s=$ $0.088,0.091,0.010$.

Ligation across the sulcus below the node produced at first lengthening of $S a-A v$ to 0.035 , and within one minute after the ligation there was auriculoventricular rhythm with $A v-S a=0.027, A s-V s=0$, cycle $=0.44$. Vagus stimulation failed to produce a return of sino-auricular rhythm, but caused the occurrence of numerous idioventricular beats.

Experiment 33.-Normally $S a-A v=0.036, A s-V s=0.18$, cycle $=0.36$. During ligation above the head of the node there occurred successively two normal 
beats, one ventricular extrasystole, one cycle, in which $S a$ and $A v$ were simultaneous and $A s-V s=0.045$, one ventricular extrasystole, one normal beat, one ventricular extrasystole, one auriculoventricular beat with $A v-S a=0.03$, $A s-V s=0$, one ventricular extrasystole, two normal beats, one ventricular extrasystole with retrograde conduction $(V s-A s=0.08$ ), one ventricular extrasystole. Then normal cycles continued with $S a-A v=0.045, A s-V s=0.16$, cycle $=0.37$.

Ligation of sulcus below the sino-auricular node now caused successively one cycle with $A v-S a=0.07, V s-A s=0.065$, one cycle with $S a-A v=0.02$, $A s-V s=0$, one cycle with $S a-A v=0.03, A s-V s=0.135$, then continuance of normal cycles with $S a-A v=0.04, A s-V s=0.14$, cycle $=0.43$.

Clamping the tissue along the intercaval borders of the node produced auriculoventricular rhythm with $A v-S a=0.019, A s-V s=0.10$, cycle $=0.49$. The onset of this rhythm was abrupt. No further influence was exerted by a cut along the auricular border of the sulcus.

EXPERIMENT 34.-Normally $S a-A v=0.022, A s-V s=0.15$, cycle $=0.54$. Ligation across the sulcus below the node produced temporary reversal of the galvanometer on the sino-auricular node, then $S a-A v$ increased to $0.05, A s-V s$ increased to 0.17 , and the cycle to 0.50 . Later $S a-A v$ shortened to 0.03 . Ligation across the sulcus above the head of the node produced several ectopic beats; then $S a-A v$ increased to $0.045, A s-V s=0.18$, cycle $=0.47$. Clamping along the intercaval border of the sulcus increased $S a-A v$ to 0.05 , and one minute later abrupt onset of auriculoventricular rhythm occurred, with $A v-S a=$ $0.014, A s-V s=0.13$, cycle $=0.62$. The clamp was now removed and placed along the auricular border of the sulcus. Following the loosening of the clamp, sino-auricular thythm returned, with $S a-A v=0.03, A s-V s=0.17$, cycle $=$ 0.47 (Fig. 1). Clamping the auricular border of the sulcus produced sinoauricular and sinoventricular heart block. The results are shown in Figures 2 and 3. In the record (Fig. 2) the upper galvanometer curve records the activity of the sino-auricular node, the lower the auriculoventricular node. The upper tambour curve records, by its downstroke, mechanical systole of the right auricle; the lower, mechanical systole of the right ventricle. It will be seen that each period of activity in the sino-auricular node is followed by activity in the auriculoventricular node, but progressively later. The $S a-A v$ conduction period thus gradually lengthens until complete failure of conduction occurs. Three records made in the course of three minutes during this condition show that usually it was every sixth sino-auricular impulse which was blocked. Occasionally every fifth or every sixth sino-auricular impulse failed to be conducted. The condition may therefore be termed 6 to 5 and 5 to 4 partial sino-auricular and sinoventricular block. There was a small open path of tissue about $4 \mathrm{~mm}$. wide between the lower end of the clamp and the ligature across the lower part of the sulcus. Clamping this region did not increase the degree of block, but produced prompt auriculoventricular rhythm.

Experiment 35.-Normally $S a-A v=0.013, A s-V s=0.10$, cycle $=0.36$. Tying a ligature across the sulcus below the node caused at first three ectopic beats, then normal cycles, but with increased $S a-A v$ conduction $(0.024)$. This returned after removal of this ligature, to 0.015 of a second. Ligation across the sulcus above the node lengthened $S a-A v$ to 0.04 , but caused no further change. Tying a ligature below the node again produced in succession one normal cycle with $S a-A v=0.036, A s-V s=0.12$; one auriculoventricular cycle with $A v-S a=0.32$, $A s-V s=0.048$; one cycle with $S a$ and $A v$ simultaneous, $A s-V s=0.08$; and then normal cycles with $S a-A v=0.036, A s-V s=0.105$, cycle $=0.38$. One-half minute later the condition was the same, one minute later $S a$ and $A v$ were found to be simultaneous; $A s-V s=0.035$, cycle $=0.45$. The next record, 
one-half minute later, showed $V s-A s=0.02$, cycle $=0.53$, and one minute later a definite auriculoventricular rhythm was evident with $A v-S a=0.02, A s-V s=$ 0.03 , cycle $=0.50$. The change to definite auriculoventricular rhythm was thus gradual. At no time was there evidence of partial block. The auriculoventricular rhythm was permanent. Vagus stimulation temporarily lengthened $A s-V s$ to 0.085 , but caused no change in the seat of impulse formation. ${ }^{13}$ 